Case Report

\title{
Morbimortality of Stroke in Dakar: An Unusual Pulmonary Complication
}

\author{
Sow Adjaratou Dieynabou ${ }^{1, ~}$, Ewodo Touna Hilaire Dominique ${ }^{1}$, Coudjou Ghislain De Chacus ${ }^{1}$, \\ Saphou-Damon Michel-Arnaud ${ }^{1}$, Ekanmian Brandon Gael ${ }^{1}$, Basse Anna Modji ${ }^{1}$, \\ Atsa Kouda Daniel ${ }^{2}$, Frank Ladys Banzouzi ${ }^{1}$, Amadou Gallo Diop ${ }^{1}$ \\ ${ }^{1}$ Neurological Clinic Ibrahima P. Ndiaye, Fann Hospital University - Cheikh Anta Diop University of Dakar (UCAD), Dakar, Senegal \\ ${ }^{2}$ CURY, Emergency Center of Yaounde, Yaoundé, Cameroon
}

\section{Email address:}

sowads@gmail.com (S. A. Dieynabou), hilairetouna@gmail.com (E. T. H. Dominique), dechacusghislain@gmail.com (C. G. De Chacus), map.saphoudamon@gmail.com (Saphou-Damon Michel-Arnaud), ekanmian2@gmail.com (E. B. Gael), basse_anna@yahoo.fr (B. A. Modji), atsakouda@gmail.com (A. K. Daniel), banzouziladys@yahoo.fr (F. L. Banzouzi), agallodiop@gmail.com (A. G. Diop)

${ }^{*}$ Corresponding author

\section{To cite this article:}

Sow Adjaratou Dieynabou, Ewodo Touna Hilaire Dominique, Coudjou Ghislain De Chacus, Saphou-Damon Michel-Arnaud, Ekanmian Brandon Gael, Basse Anna Modji, Atsa Kouda Daniel, Frank Ladys Banzouzi, Amadou Gallo Diop. Morbimortality of Stroke in Dakar: An Unusual Pulmonary Complication. Clinical Neurology and Neuroscience. Vol. 4, No. 2, 2020, pp. 33-37. doi: 10.11648/j.cnn.20200402.13

Received: May 20, 2020; Accepted: June 1, 2020; Published: June 16, 2020

\begin{abstract}
Introduction: In sub-Saharan Africa, acute stroke management is lacking, as is etiological research and gestion of the common complications, often resulting in patients' death. Atelectasis, is the complete or partial collapse of an area (lobe) of the lung; it is one of the most common respiratory complications after surgery. However, atelectasis is a relatively rare lung disease following a stroke. Case presentation: We report the case of an 84-year-old man, non-alcoholic-smoking and irregularly followed for high blood pressure on a heart disease for several years. He suddenly presented a right brachiofacial spastic hemiplegia with aphasia, rapidly followed by consciousness' troubles correlated with a mixed-mechanism ischemic stroke: embolic and atheromatus. After clinical improvement under symptomatic treatment, he suddenly presented an acute febrile respiratory distress at day 7 of hospitalization causing a suspected pulmonary embolism but with evidence on thoracic CT scan of a bilateral pleuropneumopathy with near-total atelectasis of the left lung. Evolution was unfavourable after a 15-day transitional improvment. Conclusions: Although unusual, an pulmonary atelectasis should be sought in cases of acute rebellious respiratory distress on a patient with a stroke. Management must be quick and collaborative to improve prognosis. Also, it is essential in our African context to systematize and repeat chest X-rays in case of leukoariosis on brain imaging, which is a fertile ground for the occurrence of pseudo-bulbar disorders, especially deglutition troubles.
\end{abstract}

Keywords: Morbimortality, Stroke, Atelectasis, Senegal

\section{Introduction}

Stroke is a public health problem, identified as the second leading cause of death worldwide in 2016 [1]. Management of the acute stage is difficult due to the existence of several complications, the most common of which are lung infection $(22 \%)$, urinary tract infection (24\%), bedsores (18\%) pulmonary embolism (1\%), and depression $(16 \%)[2,3]$; so that a holistic approach is needed. Atelectasis, which translates the complete or partial collapse of all or one area (lobe) of the lung is one of the most common respiratory complications after surgery. It is also reported in other lung diseases, including cystic fibrosis, lung tumors, chest injuries, pulmonary pleurisy. Nevertheless, atelectasis is not described as a common complication of stroke, although some cases have been reported in the literature [4]. In Africa, the management of acute stroke is laborious because delayed etiological research usually results in the death of patients [5]. This observation relates the case of a patient with an unusual post-stroke pulmonary complication, in which management 
and fatal outcome make it crucial to establish multidisciplinary functional neurovascular units with clear identification of reference specialists in all areas.

\section{Method}

\subsection{Framework}

Senegal is a country located on the west coast of Sub-Saharan Africa, in tropical area. It is a "developing" country with an area of $196,722 \mathrm{~km} 2$ populated by $16,705,608$ million inhabitants, of which more than $42 \%$ are under 15 years old. Health coverage falls under World Health Organization (WHO) standards with a ratio in 2015 of less than one doctor and one nurse per 15,000 inhabitants, one neurologist per 600,000 people. Until January 2020 , there was only one Neurology department, built since colonial times in the capital Dakar, with a capacity of 53 beds, 6 of which are dedicated to intensive care unit (ICU). Strokes are the first pathology with a significant morbi-mortality.

\subsection{Patients and Method}

We report the case of a patient hospitalized during the year 2019 for more than a month for an ischemic stroke in communal rooms and then in the intensive care unit after presenting a respiratory trouble which was later correlated with an unusual complication.

\section{Case Report}

This is Mr. D, an 84-year-old retired teacher who lives in Guediawaye on the outskirts of Dakar. He was received on January 10, 2019 for right hemicorporal deficit and language disorders of sudden occurrence the same day at midday. This clinical table had needed a prompted consultation in the Community Health Centre and then the neurology department at Fann University Hospital, where he was kept in communal room.

In his past medical record, the patient was neither an alcohol or tobacco user, but was known to be hypertensive for several years treated with Captopril. He was also followed for undocumented heart disease under diuretics and digitalis.

On admission, the general condition was good with no signs of dehydration or undernutrition, with a systolic high blood pressure grade 3 to $180 / 80 \mathrm{~mm}$ hg correlated with a pulse at 94 beats $/ \mathrm{min}$. The evaluation of the other parameters objected a blood oxygen saturation) at $96 \%$ with a respiratory rate at 20 cycles/minute for a temperature of 37.6 degrees Celsius.

Neurologically, the patient was drowsy but awakening under stimuli, with motor aphasia, a Glasgow coma scale of 10/15 (E4V1M5). He had a predominantly brachiofacial right spastic hemiplegia with an muscle strength, according to the MRC scale, estimated at $0 / 5$ in the right upper limb and 3/5 in right lower limb, with no sensory disorders, no meningeal signs, no damage to the cranial nerves. The cardiovascular examination showed a lowered's peak shock to the 6th intercostal space deviated to the left with auscultatory tachyarythmia and an apexian systolic breath at $2 / 6$. However, the peripheral pulses were well perceived and symmetrical without carotid breath. On pulmonary examination, the thorax was symmetrical, with vocal vibrations and a vesicular murmur well perceived at both pulmonary symmetrical fields without over-added noise. The rest of the physical examination was uncharted.

The hypothesis of a stroke was made with a request for a brain computed tomography done seven hours from the onset of clinical signs. It showed an important cortico-subcortical atrophy more marked in bi-parieto-temporal areas with an appearance of leukoariosis, without any new lesions (Figure 1). The diagnosis of recurrent ischemic stroke was accepted with suspicion of a mixed's mechanism on regard of his medical history even though atheromatosus had been the more considered. Thus, biology revealed mixed dyslipidemia (Total cholesterol - $1.81 \mathrm{~g} / \mathrm{l}$; HDL - 0.33g/l; LDL - 1.25g/l; TG $1.13 \mathrm{~g} / \mathrm{l})$. In addition, fasting blood glucose $(1,06 \mathrm{~g} / \mathrm{l})$, blood ionogram $(\mathrm{Na} / \mathrm{K}-/ \mathrm{cl}-149 / 3.3 / 113)$ and creatininemia $(11.7 \mathrm{mg} / \mathrm{l})$ were normal, as was hemoglobinemia at $16.4 \mathrm{~g} / \mathrm{L}$. The cardiac echography performed was without particularity.

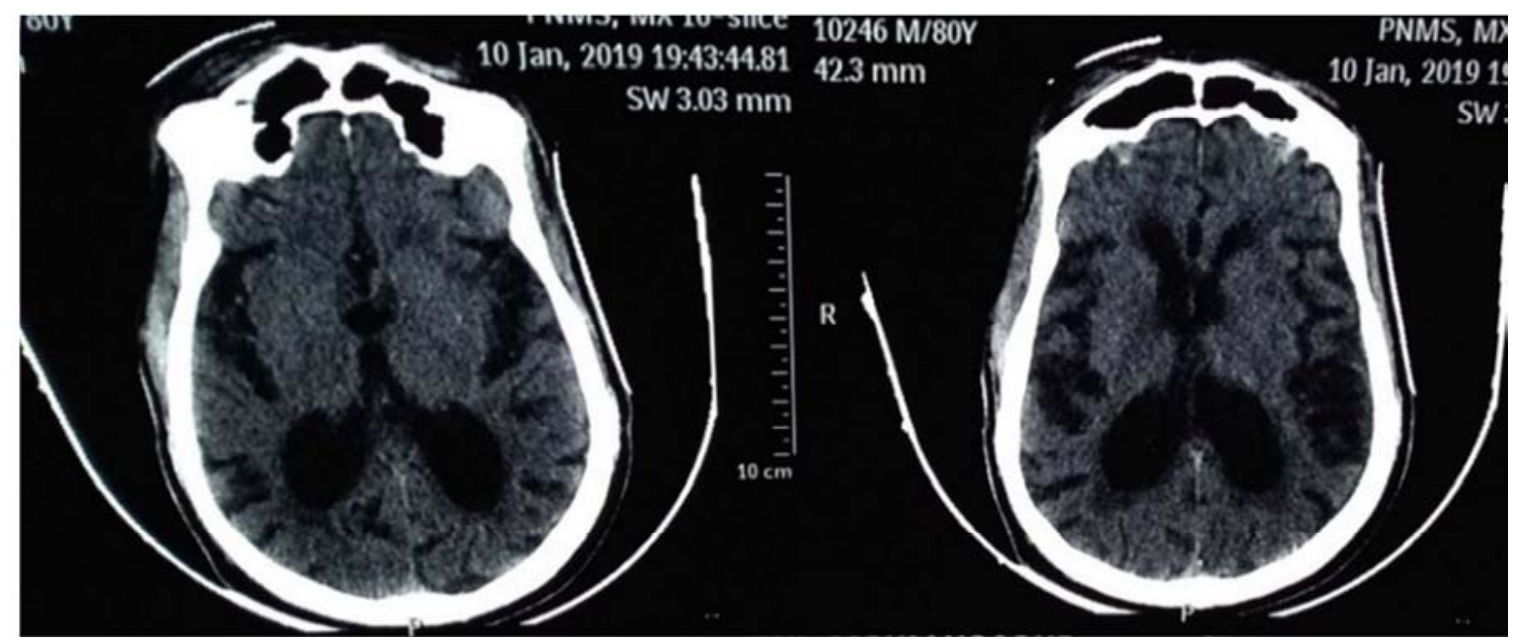

Figure 1. Early cerebral CT scan showing significant cortico-subcortical atrophy more marked in bi-parieto-temporal with an aspect of leucoariosis, without any recent lesion. 
The patient was treated by Aspirin 100mg daily, Indapamide $10 \mathrm{mg}$, Perindopril $5 \mathrm{mg}$ once daily, salt serum infusion, and nasogastric tube feeding three times a day, in addition to heparin $4000 \mathrm{UI}$ once a day.

During evolution, after a time of partial recovery the patient presented suddenly on day 10 of hospitalization an episode of respiratory distress with tachyarrhythmia and psychomotor agitation, pointing to a suspicion of a pulmonary embolism associated with recurrent stroke. The electrocardiogram showed an irregular sinusal rhythm, atrial and ventricular extrasystoles and left ventricular hypertrophy. Standard X-ray showed atelectasis of the entire left lung (Figure 2). Blood numeration showed an inflammatory syndrom, infectious-looking, with C-reactive protein at $95 \mathrm{mg} / 1$, polynuclear neutrophil hyperleucocytosis at 11,000 whites/litre $(11 \times 109)$ and limited thrombopenia at 210 .

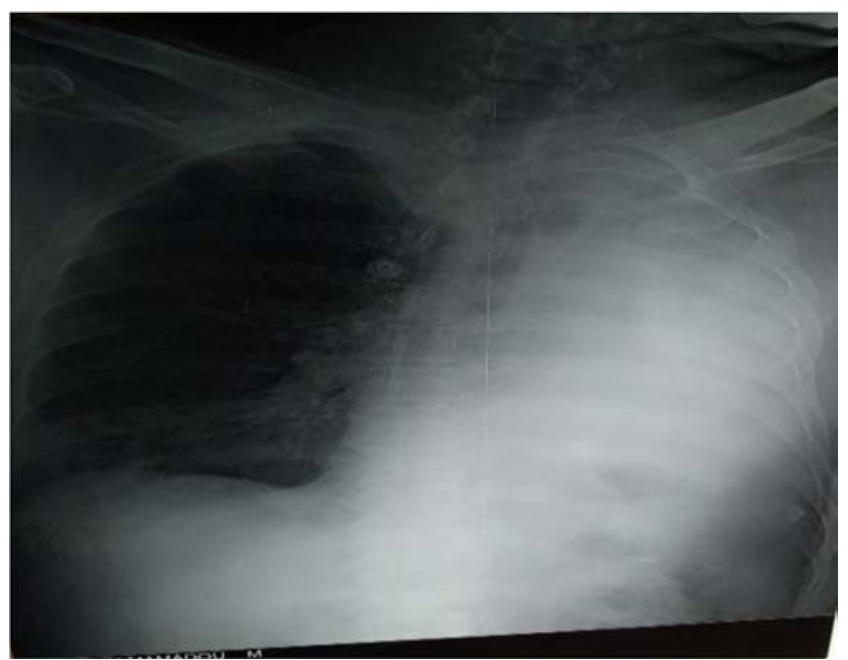

Figure 2. Thorax X-ray showing left atelectasis.

He was then admit to ICU with an oxygen therapy. Aspirin was immediately stopped, and a probabilistic antibiotherapy combining Ceftriaxone $2 \mathrm{~g}$ per day for seven days, intramuscular injunction of $160 \mathrm{mg}$ Gentamycin over 5 days was started. Oral Amoxicillin associated with Clavulanic acid $1 \mathrm{~g}$ three times a day for 15 days followed the IV antibiotic. Pneumological and cardiological opinions were given with the request of thoracic computed tomography and/or fiberscope and then, an anticoagulation (Enoxaparin at $6000 \mathrm{IU} \times 2 /$ day) associated to Digoxin $0.25 \mathrm{~g}$ per day had been advised.

At day 20 of hospitalization, the patient clinical 'state deteriorated with the deepening of Glasgow coma scale $(6 / 15)$ and the appearance of fever and dark urines.. A Thoracic CT scan was performed with evidence of bilateral pleuro-pneumopathy associated with the left pulmonary atelectasis (Figure 3).

The control of blood count confirmed the clinical worsening with an increase in leukocytes to $12000 / \mathrm{mm}^{3}$ predominantly neutrophilic, a decrease in hemoglobin to $13.1 \mathrm{~g} / \mathrm{l}$ and an increase in CRP to $200 \mathrm{mg} / 1$. urinalysis showed pseudomonas aeruginosa sensitive to Ciprofloxacin. The blood ions were normal $(\mathrm{Na}+\mathrm{K}+/ \mathrm{Cl}-:$ 135/4.5/102 meq/l) and the INR at 1.23. A bronchial aspiration every 3 hours was instituted with respiratory physiotherapy and put on Ciprofloxacin $500 \mathrm{mg} \times 2$ a day.

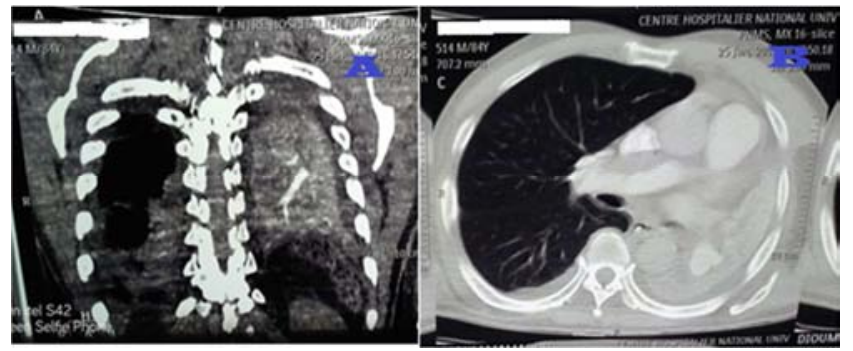

Figure 3. Thorax CT-Scan A: coronal section B: axial section showing bilateral pleural fluid effusion of medium abundance. On the left is pulmonary parenchymal atelectasis with a collapsed lung.

On day 40 of hospitalization, a stable apyrexia was obtained, a disappearance of the respiratory distress, and the improvement of the state of consciousness on the persistent right hemiplegia. Radiological evolution was also good with near disappearance of pulmonary atelectasis on radiographic control (Figure 4).

However, five days later, the patient died in a context of recrudescency of acute respiratory distress.

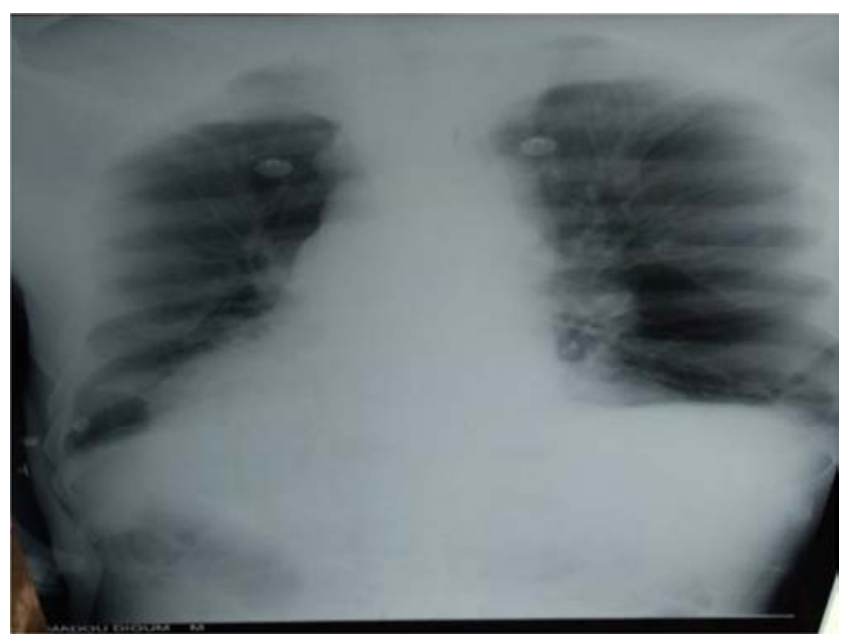

Figure 4. Control thorax X-Ray showing disappearance of atelectasis.

\section{Discussion}

Respiratory distress syndrome accounts for $15 \%$ of complications in patients hospitalized in stroke resuscitation in Senegal [6], 3.6\% in China [7] 4\% in the USA [8]. These are generally dominated by pneumonia and pulmonary embolism [9]. Our patient had presented an acute respiratory distress in a context of cardiac fibrillation on day 7 th after stroke. Thus pulmonary embolism was discussed in front of epidemiological data, including hospitalization and immobilization, which increase the risk of thromboembolism $[10,11]$, acute respiratory distress with tachyarrhythmia, respectively, by 8 and 2 times. However, the D-dimer was not done, and the chest CT scan was not in favor of pulmonary 
embolism. Pneumonia was evoked because of its frequency as an acute complication of a stroke [2, 12, 13], but also in front of the respiratory distress added to the biological inflammatory syndrome; Chest X-ray showed a unilateral homogenous opacity on the left without an air bronchogram confirmed by the chest CT scan. In several multicenter studies in acute stroke, pulmonary atelectasis was not found amongst the usual complications [14, 15]. Pulmonary atelectasis, described as the loss of lung volume due to collapse of lung tissue, is exceptional and usually occurs either by obstructive bronchial mechanisms by foreign bodies, tumors or mucus plug [16]; or by non-obstructive mechanisms such as loss of contact between the pleura and the lung, loss of surfactant, or replacement of the parenchymal tissue with scar tissue or infiltrative disease [10].

For our patient, the obstructive mechanism by mucus plug seems to be the most probable mechanism, similar to the case reported by Karanam in India who found mucus plug as the cause of atelectasis after bronchoscopy of 60 years old women presenting ischemic stroke [4]. However, in our case, bronchoscopy was not done for seeing the mucus plug. Management consisted of oxygen therapy, respiratory physiotherapy, and antibiotics combined with Digitalis and enoxaparin as arrhythmia therapy. The evolution of atelectasis was excellent, as shown by the chest X-ray. However, death occurred in a context of sudden recrudescency of respiratory disease suggesting a re-ocurrence of atelectasis, pulmonary embolism, or cardiopathy. An autopsy could have helped confirm or refute these different hypotheses.

\section{Conclusion}

Pulmonary atelectasis is an unusual complication of stroke in acute phase. However, it may be caused by bronchial obstruction by mucus plug hence the interest of regularly aspiration and earlier physiotherapy in case of disorders of consciousness. Also, it is essential in our African context to systematize and repeat chest X-rays in case of leukoariosis on brain imaging, which is a fertile ground for the occurrence of pseudo-bulbar disorders, especially deglutition troubles.

\section{Recommendations}

This original clinical case, which is unusual in our daily practice, has been a source of difficulties in multidisciplinary coordination of care. He objectified the limits of our care system without central coordination but above all fluid inter-service collaboration. The necessity of a multidisciplinary unit, or at least consultation, in case of systemic or serious pathologies, seems obvious.

\section{Conflict of Interest Statement}

We assure you that there is no conflict of interest, the ultimate goal being the only scientific interest with the result that all aspects of internal medicine are taken into account in daily neurological practice.

\section{Acknowledgements}

Thanks to all the medical and paramedical staff in the neurological intensive care unit for their dedication and determination to keeping patients alive.

\section{References}

[1] WHO: International Classification of Functioning, Disability and Health (ICF). Disponible sur: https://www.who.int/classifications/icf/en/ [cité 3 déc 2019].

[2] Langhorne P, Stott DJ, Robertson L, MacDonald J, Jones L, McAlpine C, et al. (2000) Medical complications after stroke: a multicenter study. Stroke; 31 (6): 12239.

[3] Kumar S, Selim MH, Caplan LR. (2010) Medical complications after stroke. Lancet Neurol. Janv; 9 (1): 10518.

[4] Gowrinath K, Reddy GV. (2017) Acute total lung collapse in a woman with Acute Stroke and Atrial Fibrillation. J Clin Diagn Res JCDR - Fev; 11 (2): OJ078.

[5] Adoukonou TA, Vallat J-M, Joubert J, Macian F, Kabore R, Magy L, et al. (2010) Prise en charge des accidents vasculaires cérébraux en Afrique subsaharienne. Rev Neurol (Paris) - Nov; 166 (11): 88293.

[6] Sène Diouf F, Mapoure Y, Ndiaye M, Mbatchou Ngahane BH, Touré K, Thiam A, et al. (2008) Survie des accidents vasculaires cérébraux comateux à Dakar (Sénégal). Rev Neurol - Mai; 164: 4528.

[7] Zhao J, Liu Y, Li H. (2015) Aspiration-related acute respiratory distress syndrome in acute stroke patient. PloS One; 10 (3): e0118682.

[8] Rincon F, Maltenfort M, Dey S, Ghosh S, Vibbert M, Urtecho J, et al. (2014) The prevalence and impact of mortality of the acute respiratory distress syndrome on admissions of patients with ischemic stroke in the United States. J Intensive Care Med. Dec; 29 (6): 35764.

[9] Rochester CL, Mohsenin V. (2002) Respiratory complications of stroke. Semin Respir Crit Care Med. Juin; 23 (3): 24860.

[10] Blondon M, Le Gal G, Righini M. (2010) Stratégie diagnostique et intérêt comparatif des scores cliniques pour le diagnostic d'embolie pulmonaire. Rev Médecine Interne Nov; 31 (11): 7429.

[11] Eswaradass PV, Dey S, Singh D, Hill MD (2018). Pulmonary embolism in ischemic stroke. Can J Neurol Sci.; 45 (3): 3435.

[12] Wagner C, Marchina S, Deveau JA, Frayne C, Sulmonte K, Kumar S. (2016) Risk of stroke-associated pneumonia and oral hygiene. Cerebrovasc Dis Basel Switz.; 41 (12): 359.

[13] Pongmoragot J, Rabinstein AA, Nilanont Y, Swartz RH, Zhou L, Saposnik G, et al. (2013) Pulmonary embolism in ischemic stroke: clinical presentation, risk factors, and outcome. $\mathrm{J} \mathrm{Am}$ Heart Assoc. Nov; 2 (6): e000372.

[14] Martina Reiten Bovim, Torunn Askim, Stian Lydersen, Hild Fjærtoft, Bent Indredavik. (2016) Complications in the first week after stroke: a 10-year comparison. BMC Neurol.; 16: 133. Published online 2016 Aug 11. doi: 10.1186/s12883-016-0654-8. 
[15] Di Carlo A, Lamassa M, Franceschini M, Bovis F, Cecconi L, Pournajaf S, et al. (2018) Impact of acute-phase complications and interventions on 6-month survival after stroke. A prospective observational study. PloS One.; 13 (3): e0194786.

\section{Biography}

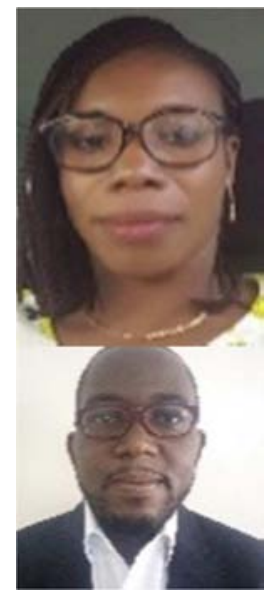
the Cheikh Anta Diop University of Dakar. University of Dakar.
[16] Tarun Madappa. (2018) Atelectasis: background, pathophysiology, etiology. Disponible sur: https://emedicine.medscape.com/article/296468-overview Dec 06, [cité 2 juin 2019].

SOW Adjaratou Dieynabou is a Senegalese neurophysiologist, epileptologist and neuropediatrician, responsible of the intensive care unit in the department of neuroscience of Fann's teaching hospital. She is a professor-researcher at

Ewodo Touna Hilaire Dominique is a Cameroonian doctor, resident in neurology at the Cheikh Anta Diop 